\title{
Serum Testosterone Levels Are Not Modified by Vitamin D Supplementation in Dialysis Patients and Healthy Subjects
}

\author{
Christof Ulrich $^{\mathrm{a}}$ Bogusz Trojanowicz ${ }^{\mathrm{a}}$ Roman Fiedler ${ }^{\mathrm{a}}$ Frank Bernhard Kraus ${ }^{\mathrm{b}}$ \\ Gabriele I. Stanglc Matthias Girndt ${ }^{\mathrm{a}}$ Eric Seibert ${ }^{\mathrm{a}, \mathrm{d}}$

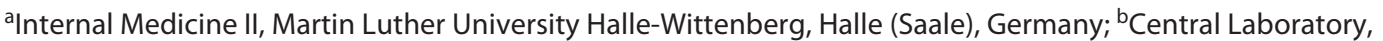 \\ University Hospital Halle (Saale), Halle (Saale), Germany; ' Institute of Agricultural and Nutritional Sciences, Martin \\ Luther University Halle-Wittenberg, Halle (Saale), Germany; dNephrologische Kooperation Villingen-Schwenningen, \\ Villingen-Schwenningen, Germany
}

\section{Keywords}

Hemodialysis · Vitamin D · Testosterone

\begin{abstract}
Introduction: Low serum testosterone is related to increased mortality in male dialysis patients. An association of vitamin D status with serum androgen levels with concordant seasonal variation has been described, but it is undecided whether vitamin D supplementation improves testosterone levels. Methods: In a randomized, placebo-controlled, and double-blind manner, we investigated the effects of an oral vitamin D supplementation in healthy subjects and hemodialysis patients on testosterone levels. One hundred three healthy individuals received cholecalciferol 800 IE/day $(n=$ 52 ) or placebo $(n=51)$ for 12 weeks. Thirty-three hemodialysis patients received cholecalciferol adapted to their serum levels following current guidelines $(n=15)$ or placebo $(n=$ 18) for 12 weeks. Results: In healthy individuals, 25(OH)D3 levels rose significantly in the verum group $(38.1 \pm 13.7$ vs. $72.5 \pm 15.4 \mathrm{nmol} / \mathrm{L}, p<0.001)$, whereas in the placebo group, levels dropped ( $37.7 \pm 14.7$ vs. $31.9 \pm 13.1, p<0.001)$. Testosterone levels did not change significantly (verum, males: $20.9 \pm 6.6$ vs. $20.5 \pm 7.9 \mathrm{nmol} / \mathrm{L}, p=0.6$; verum, females: 0.9
\end{abstract}

karger@karger.com www.karger.com/nef

Karger $\stackrel{\text { ' }}{5}$

bOPEN ACCESS
(C) 2021 The Author(s)

Published by S. Karger AG, Basel

This is an Open Access article licensed under the Creative Commons Attribution-NonCommercial-4.0 International License (CC BY-NC) (http://www.karger.com/Services/OpenAccessLicense), applicable to the online version of the article only. Usage and distribution for commercial purposes requires written permission. \pm 0.5 vs. $0.92 \pm 0.5, p=0.4$; placebo, males: $18.5 \pm 10.2$ vs. 21.8 $\pm 16.5, p=0.07$, placebo, females: $1.6 \pm 4.2$ vs. $1.6 \pm 4.9, p=$ $0.6)$. In dialysis patients, the mean cholecalciferol level was only $32.3 \pm 17.8 \mathrm{nmol} / \mathrm{L}$, with only $2 \%$ of the values being within the normal range. Cholecalciferol levels normalized in the verum group $(29.4 \pm 11.2$ vs. $87.8 \pm 22.3, p<0.001)$, whereas levels dropped further in the placebo group (33.6 \pm 16.6 vs. $24.6 \pm 8.0 \mathrm{nmol} / \mathrm{L}, p<0.001)$. Testosterone levels did not change significantly (verum, males: $8.0 \pm 3.7$ vs. $7.8 \pm 3.8$, $p=0.8$; verum, females: $1.3 \pm 1.0$ vs. $1.2 \pm 1.0 \mathrm{nmol} / \mathrm{L}, p=0.5$; placebo, males: $11.9 \pm 5.0$ vs. $11.6 \pm 4.0 \mathrm{nmol} / \mathrm{L}, p=0.6$; placebo, females: $0.8 \pm 0.5$ vs. $0.7 \pm 0.4 \mathrm{nmol} / \mathrm{L}, p=0.8$ ). Conclusion: Serum testosterone levels in hemodialysis patients and healthy individuals are independent from vitamin $D$ status and cannot be significantly increased by cholecalciferol supplementation.

(c) 2021 The Author(s).

Published by S. Karger AG, Basel

\section{Introduction}

High mortality and morbidity are still mostly challenging in CKD patients. Apart from traditional risk factors, it has been demonstrated that low serum testoster- 
one is related to increased mortality and other adverse clinical outcomes in male hemodialysis patients $[1,2]$. Likewise, in healthy aged men, low serum testosterone levels were associated with reduced survival rates [3-5]. On the other hand, exogenous replacement therapy is linked to adverse events as well [6]. Even in postmenopausal women on hemodialysis, low serum concentration of testosterone is associated with atherosclerosis [7]. In addition, in earlier stages of $\mathrm{CKD}$, higher serum testosterone concentration has beneficial effects on muscle strength and fat-free mass [8]. Wehr et al. [9] found an association of vitamin D status with serum androgen levels with concordant seasonal variation in a cohort of men suffering from cardiovascular diseases and are supported by Wang et al. [10] who confirmed a higher prevalence of hypogonadism in Chinese men suffering from vitamin D deficiency. In Malaysian men, this association was less robust and dependent on BMI [11]. Data from prospective investigations are scarce and contradictory: a post hoc analysis of 3 smaller populations denied a link between vitamin $\mathrm{D}$ supplementation and increasing levels of circulating testosterone [12]. In contrast, vitamin D supplementation resulted in an increase of serum testosterone concentrations in a group of 54 adipose, nondiabetic males [13].

The different findings show that the role of vitamin D in maintaining the testosterone levels in serum still needs to be clarified. This study aimed to investigate the effect of vitamin D supplementation in healthy volunteers and chronic hemodialysis patients in a prospective, randomized, placebo-controlled, and double-blind manner.

\section{Materials and Methods}

One hundred five apparently healthy participants (20-71 years old) were randomized using a computer-generated randomization schedule with a 1:1 allocation ratio to receive 800 IE cholecalciferol/day - as recommended by the nutrition societies in Germany, Austria, and Switzerland - for 12 weeks (total $n=54 ; 36$ females and 18 males) or placebo (total $n=51 ; 34$ females and 17 males) in parallel groups. Investigators and participants were blinded to treatment allocation. Among others, exclusion criteria included intake of prescription medication, deviations in blood count, or metabolic disorders as described previously $[14,15]$. Baseline demographics are summarized in Table 1.

The study (Clinical trial registration number at clinicaltrails. gov: NCT01711905) was conducted in Halle (Saale), Germany $\left(51^{\circ}\right.$ northern latitude) from January to April and was approved by the Local Ethics Committee of the Medical Faculty at the Martin Luther University Halle-Wittenberg.

In addition, 38 hemodialysis patients were randomized with a 1:1 allocation ratio to treatment in parallel groups to receive
Table 1. Baseline demographics of healthy participants

\begin{tabular}{lll}
\hline & $\begin{array}{l}\text { Placebo group } \\
(n=51)\end{array}$ & $\begin{array}{l}\text { Verum group } \\
(n=54)\end{array}$ \\
\hline Age, years & $39 \pm 14$ & $39 \pm 14$ \\
Gender (male/female) & $17 / 34$ & $18 / 36$ \\
BMI, kg/m & $24 \pm 3$ & $24 \pm 3$ \\
\hline
\end{tabular}

Table 2. Baseline demographics of dialysis patients

\begin{tabular}{|c|c|c|}
\hline & $\begin{array}{l}\text { Placebo group } \\
(n=18)\end{array}$ & $\begin{array}{l}\text { Verum group } \\
(n=15)\end{array}$ \\
\hline Age, years & $67.4 \pm 9.8$ & $66.9 \pm 10.8$ \\
\hline Gender (male/female) & $9 / 9$ & $9 / 6$ \\
\hline Dialysis vintage, years & $1.6(0.6-8.2)$ & $2.6(0.3-13.8)$ \\
\hline Dry body weight, kg & $71.3 \pm 12.6$ & $83.3 \pm 17.0$ \\
\hline \multicolumn{3}{|c|}{ Vitamin D medication, $n /($ mean dose $)$} \\
\hline None & 9 & 7 \\
\hline Alfacalcidol & $2(1.8 \mu \mathrm{g} / \mathrm{wk})$ & 0 \\
\hline Calcitriol & $7(1.9 \mu \mathrm{g} / \mathrm{wk})$ & $8(1.5 \mu \mathrm{g} / \mathrm{wk})$ \\
\hline \multicolumn{3}{|c|}{ Phosphate binders, $n /($ mean dose) } \\
\hline Ca-acetate & $7(3,686 \mathrm{mg} / \mathrm{d})$ & $12(4,635 \mathrm{mg} / \mathrm{d})$ \\
\hline Algeldrate & $4(1,800 \mathrm{mg} / \mathrm{d})$ & $4(2,550 \mathrm{mg} / \mathrm{d})$ \\
\hline Aluminum hydroxide & 0 & $2(900 \mathrm{mg} / \mathrm{d})$ \\
\hline Sevelamer & $9(3,689 \mathrm{mg} / \mathrm{d})$ & $4(4,300 \mathrm{mg} / \mathrm{d})$ \\
\hline Lanthanum carbonate & 0 & 0 \\
\hline Cinacalcet, $n /($ mean dose $)$ & $3(90 \mathrm{mg} / \mathrm{d})$ & $1(30 \mathrm{mg} / \mathrm{d})$ \\
\hline
\end{tabular}

Normally distributed data sets are described as mean \pm SD. Data with skewed distribution are presented as median (range).

cholecalciferol according to K/DOQI (Kidney Disease Outcomes Quality Initiative) guidelines in a level-adapted manner (total $n=15$; 9 males and 6 females) or placebo (total $n=18$; 9 males and 9 females) as described before [16]. Randomization, stratified for gender, was performed using a random number generator at the clinical pharmacy. Investigators, patients, and dialysis staff were blinded to treatment allocation. Among others, exclusion criteria included known malignancy, liver disease, defined as 2-fold upper limit of ASAT or ALAT levels, PTH levels $<50 \mathrm{pg}$ / $\mathrm{mL}$, current clinically relevant infections treated with antibiotic therapy, chronic viral infectious diseases (e.g., HIV and hepatitis $\mathrm{B}$ or $\mathrm{C}$ ), immunosuppressive medication, known hematologic disorders other than renal anemia, pseudohypoparathyroidism, sarcoidosis, intake of cardiac glycosides, and preexisting cholecalciferol supplementation. Baseline demographics are summarized in Table 2.

The study (Clinical trial registration number at clinicaltrails. gov: NCT00397475) was conducted in Homburg (Saar), Germany ( $49^{\circ}$ northern latitude) from November to March and was approved by the Institutional Review Board of the professional body of physicians of Saarland. 
Testosterone and 25(OH)D3 concentrations were analyzed before intervention and after 12 weeks. In 2 healthy participants, samples were not available for further investigation. One hemodialysis patient in the placebo group discontinued study drug medication due to nausea after 1 month. Four hemodialysis patients in the cholecalciferol group were withdrawn from analysis because of renal transplantation within the study period $(n=2)$, incomplete data acquisition $(n=1)$, or violation of exclusion criteria $(n=1$, active malignancy which was occult at study initiation).

Testosterone was measured in the Central Laboratory of the University Hospital Halle with the Elecsys Testosterone II assay (electro-chemiluminescence immunoassay; Roche Diagnostics, Mannheim, Germany) on a Roche Cobas e602 analyzer integrated in a fully automated Roche Cobas 8000 platform. All analyses on the Cobas e602 analyzer were carried out according to the manufacturer's instructions and manuals, with routine maintenance and quality control procedures.

In healthy participants, serum $25(\mathrm{OH}) \mathrm{D} 3$ concentrations were quantified by means of a MassChrom ${ }^{\circledR} 25-\mathrm{OH}$ Vitamin D3 reagent kit (Chromsystems GmbH, Munich, Germany) for LC-MS/MS using an API $2000^{\mathrm{TM}}$ system (Applied Biosystems, Darmstadt, Germany) as described elsewhere [14]. In hemodialysis patients, $25(\mathrm{OH}) \mathrm{D} 3$ concentrations were quantified by means of a Chemiluminescence Immunoassay (DiaSorin, Dietzenbach, Germany).

SPSS version 25.0 (IBM, Chicago, IL, USA) was used for statistical analyses. 25(OH)D3 and testosterone levels at baseline and after 12 weeks were compared using a paired $t$ test and are presented as the mean \pm SD. Correlation between cholecalciferol and testosterone levels was tested by Pearson's correlation. The level of significance was set at $5 \%$ for all tests.

\section{Results}

In healthy participants that received the vitamin D3 supplement, 25(OH)D3 levels increased significantly within the 12 -week study period $(38.1 \pm 13.7$ vs. $72.5 \pm$ $15.4 \mathrm{nmol} / \mathrm{L}, p<0.001)$, whereas in the placebo group, $25(\mathrm{OH}) \mathrm{D} 3$ levels dropped $(37.7 \pm 14.7$ vs. $31.9 \pm 13.1$ $\mathrm{nmol} / \mathrm{L}, p<0.001)$. Testosterone levels did not significantly change, neither in the cholecalciferol group nor in the placebo group (verum, males: $20.9 \pm 6.6$ vs. $20.5 \pm 7.9$ $\mathrm{nmol} / \mathrm{L}, p=0.6$; verum, females: $0.9 \pm 0.5$ vs. $0.92 \pm 0.5$ $\mathrm{nmol} / \mathrm{L}, p=0.4$; placebo, males: $18.5 \pm 10.2$ vs. $21.8 \pm 16.5$, $p=0.07$; placebo, females: $1.6 \pm 4.2$ vs. $1.6 \pm 4.9 \mathrm{nmol} / \mathrm{L}$, $p=0.6)$.

In hemodialysis patients, the mean $25(\mathrm{OH}) \mathrm{D} 3$ level was only $32.3 \pm 17.8 \mathrm{nmol} / \mathrm{L}$, with merely $2 \%$ of the values being within the normal range. $25(\mathrm{OH}) \mathrm{D} 3$ levels normalized in the verum group $(29.4 \pm 11.2$ vs. $87.8 \pm 22.3$ $\mathrm{nmol} / \mathrm{L}, p<0.001)$, whereas levels dropped in the placebo group $(33.6 \pm 16.6$ vs. $24.6 \pm 8.0 \mathrm{nmol} / \mathrm{L}, p<0.001)$. Just as in the healthy subjects, testosterone levels did not change significantly (verum, males: $8.0 \pm 3.7$ vs. $7.8 \pm 3.8$, $p=0.8$; verum, females: $1.3 \pm 1.0$ vs. $1.2 \pm 1.0 \mathrm{nmol} / \mathrm{L}, p=$

Serum Testosterone Levels and Vitamin D Supplementation

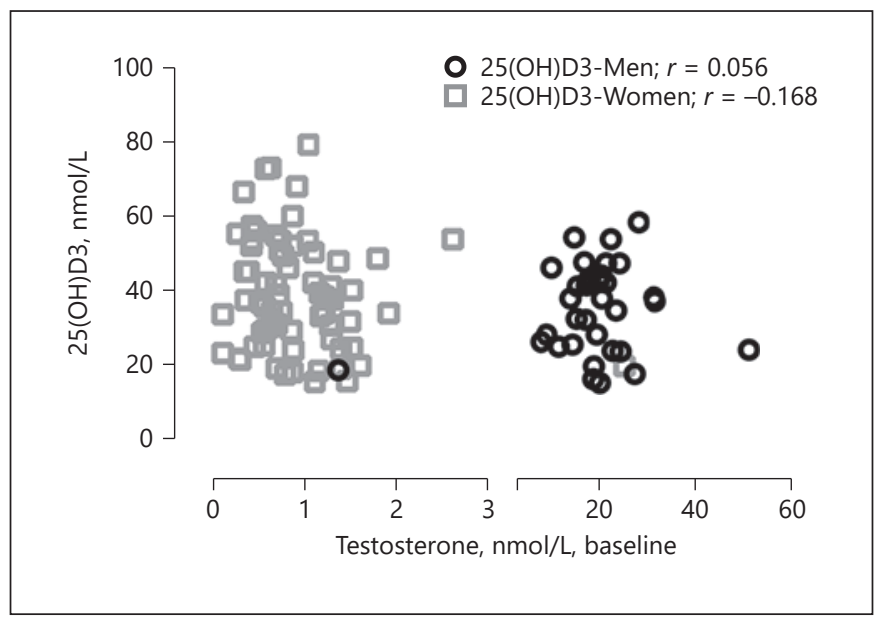

Fig. 1. Correlation of testosterone and 25(OH)D3 levels in women and men at baseline of the study.

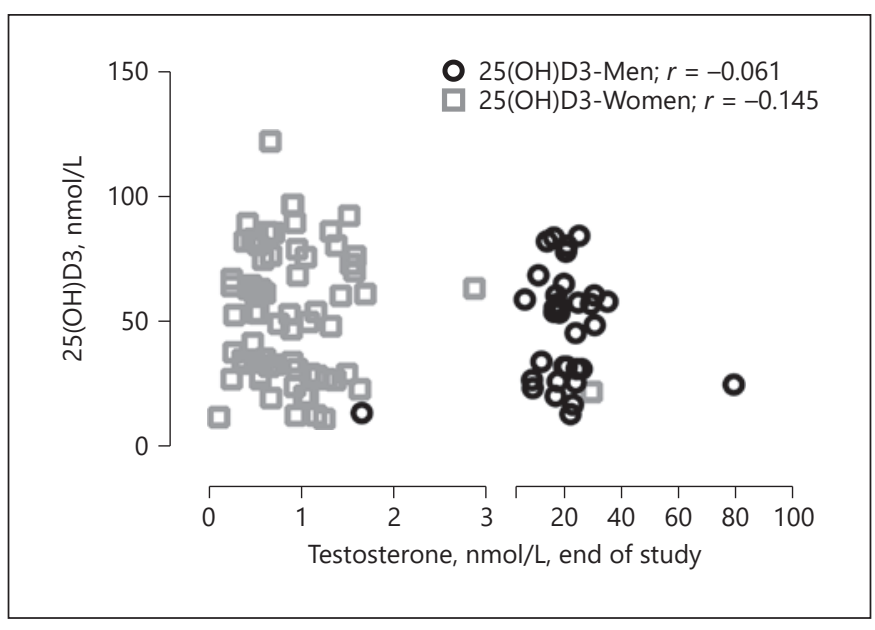

Fig. 2. Correlation of testosterone and $25(\mathrm{OH}) \mathrm{D} 3$ levels in women and men at the end of the study.

0.5; placebo, males: $11.9 \pm 5.0$ vs. $11.6 \pm 4.0 \mathrm{nmol} / \mathrm{L}, p=$ 0.6 ; placebo, females: $0.8 \pm 0.5$ vs. $0.7 \pm 0.4 \mathrm{nmol} / \mathrm{L}, p=$ $0.8)$.

There was no significant correlation between testosterone and 25(OH)D3 levels, neither at baseline (males: $r=0.056, p=0.756$; females: $r=-0.168, p=0.163$, Fig. 1 ) nor at the end of the study period (males: $r=-0.061, p=$ 0.735; females: $r=-0.145, p=0.231$, Fig. 2). To conclude, serum testosterone levels in hemodialysis patients and healthy subjects were independent from vitamin D status and may not be significantly influenced by cholecalciferol supplementation (Fig. 3, 4). 


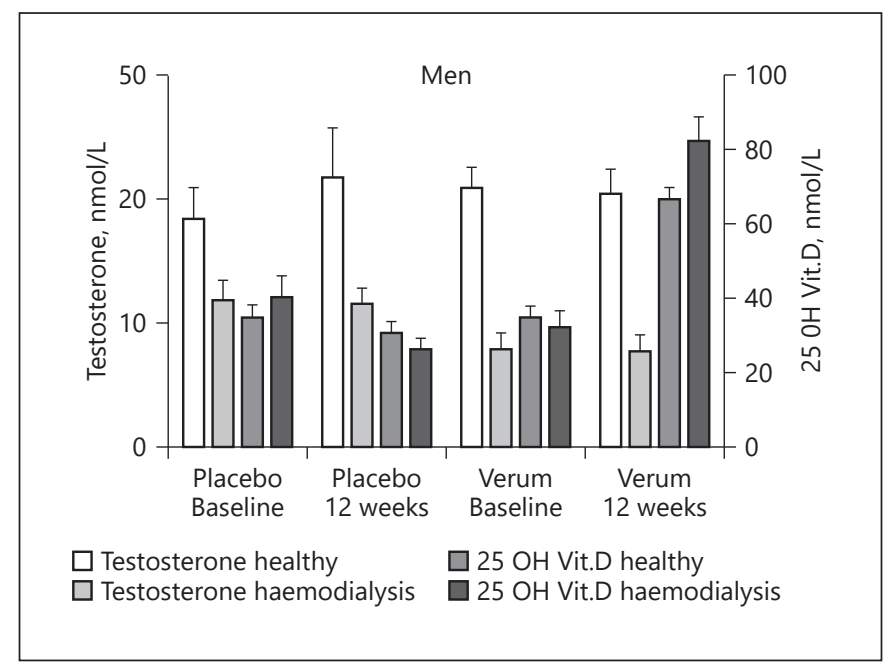

Fig. 3. Serum concentrations of $25(\mathrm{OH}) \mathrm{D} 3$ and testosterone in healthy and hemodialysis-dependent men who received either a vitamin D supplement or a placebo over a period of 12 weeks; $n=$ 35 (healthy) and $n=18$ (hemodialysis).

\section{Discussion}

This study aimed to investigate the effect of vitamin D supplementation in healthy subjects and hemodialysis patients on serum testosterone levels which has been discussed controversially in the past. Prospective data in these populations are scarce. We therefore investigated the effect of vitamin D supplementation on serum testosterone levels in a prospective, randomized, placebo-controlled, and double-blind manner. Vitamin D supplementation was capable of increasing serum 25(OH)D3 levels but had no effect on testosterone levels in males and females.

One reason might be that the investigated subjects had normal testosterone levels at baseline. It cannot be excluded that in hypogonadism, vitamin D supplementation would have had positive effects. On the other hand, Wang et al. [10] found a higher prevalence of hypogonadism in vitamin D deficiency that could not be confirmed in our populations as well. Another reason might be that the dosage of vitamin D3 was relatively low in comparison with other studies. It must be further taken into account that most of the study participants did not show severe vitamin D deficiency with 25(OH)D3 serum levels $<25 \mathrm{nmol} / \mathrm{L}$.

Also, the association of vitamin D status with serum androgen levels with concordant seasonal variation in men in a cardiovascular cohort [9] suggests a more direct

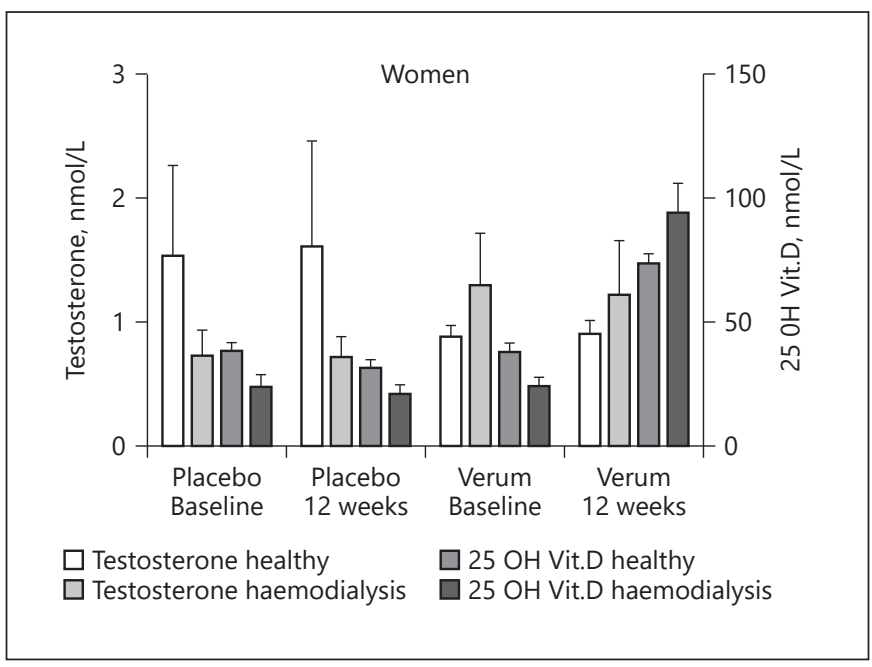

Fig. 4. Serum concentrations of $25(\mathrm{OH}) \mathrm{D} 3$ and testosterone in healthy and hemodialysis-dependent women who received either a vitamin $\mathrm{D}$ supplement or a placebo over a period of 12 weeks; $n=70$ (healthy) and $n=15$ (hemodialysis).

dependence of testosterone levels on vitamin $\mathrm{D}$ that should have been apparent in our data if there would be a causal link. At least, at baseline, in vitamin D deficiency, there should have been a correlation between both parameters which was not the case. In conclusion, we found no evidence for a causal relationship between vitamin $\mathrm{D}$ deficiency and diminished testosterone levels in healthy subjects and hemodialysis patients.

\section{Statement of Ethics}

This study was approved by the Local Ethics Committee of the Medical Faculty at the Martin Luther University Halle-Wittenberg and by the Institutional Review Board of the professional body of physicians of Saarland. All research was conducted ethically in accordance with the World Medical Association Declaration of Helsinki, and all subjects have given their written informed consent.

\section{Conflict of Interest Statement}

The authors have no conflicts of interest to declare.

\section{Funding Sources}

This work was funded in parts by a grant from the German Federal Ministry of Education and Research, Grant No. 01EA1323A. 


\section{Author Contributions}

M.G. and E.S. conceived the study. C.U., B.T., F.B.K., and E.S. conducted the study and processed the samples. C.U. and E.S. performed the statistical analyses and prepared the manuscript. B.T.,
R.F., G.I.S., M.G., and F.B.K. reviewed the literature and helped to draft the manuscript. All authors read and approved the final manuscript.

\section{References}

1 Carrero JJ, Qureshi AR, Parini P, Arver S, Lindholm B, Bárány $\mathrm{P}$, et al. Low serum testosterone increases mortality risk among male dialysis patients. J Am Soc Nephrol. 2009 Mar;20:613-20.

2 Bello AK, Stenvinkel P, Lin M, Hemmelgarn B, Thadhani R, Klarenbach S, et al. Serum testosterone levels and clinical outcomes in male hemodialysis patients. Am J Kidney Dis. 2014 Feb;63:268-75.

3 Laughlin GA, Barrett-Connor E, Bergstrom J. Low serum testosterone and mortality in older men. J Clin Endocrinol Metab. 2008 Jan;93: 68-75.

4 Shores MM, Matsumoto AM, Sloan KL, Kivlahan DR. Low serum testosterone and mortality in male veterans. Arch Intern Med. 2006 Aug;166:1660-5.

5 Araujo AB, Kupelian V, Page ST, Handelsman DJ, Bremner WJ, McKinlay JB. Sex steroids and all-cause and cause-specific mortality in men. Arch Intern Med. 2007 Jun 25; 167: 1252-60.

6 Rhoden EL, Morgentaler A. Risks of testosterone-replacement therapy and recommendations for monitoring. N Engl J Med. 2004 Jan 29;350:482-92.
7 Shiraki N, Nakashima A, Doi S, Carrero JJ, Sugiya N, Ueno T, et al. Low serum testosterone is associated with atherosclerosis in postmenopausal women undergoing hemodialysis. Clin Exp Nephrol. 2014 Jun; 18:499-506.

8 Cigarrán S, Pousa M, Castro MJ, González B, Martínez A, Barril G, et al. Endogenous testosterone, muscle strength, and fat-free mass in men with chronic kidney disease. J Ren Nutr. 2013 Sep;23:e89-95.

9 Wehr E, Pilz S, Boehm BO, März W, Obermayer-Pietsch B. Association of vitamin D status with serum androgen levels in men. Clin Endocrinol. 2010 Aug;73:243-8.

10 Wang N, Han B, Li Q, Chen Y, Chen Y, Xia F, et al. Vitamin D is associated with testosterone and hypogonadism in Chinese men: Results from a cross-sectional SPECT-China study. Reprod Biol Endocrinol. 2015 Jul 16; 13:74.

11 Chin K-Y, Ima-Nirwana S, Wan Ngah WZ. Vitamin D is significantly associated with total testosterone and sex hormone-binding globulin in Malaysian men. Aging Male. 2015; 18:175-9.
12 Heijboer AC, Oosterwerff M, Schroten NF, Eekhoff EMW, Chel VGM, de Boer RA, et al. Vitamin D supplementation and testosterone concentrations in male human subjects. Clin Endocrinol. 2015 Jul;83:105-10.

13 Pilz S, Frisch S, Koertke H, Kuhn J, Dreier J, Obermayer-Pietsch B, et al. Effect of vitamin D supplementation on testosterone levels in men. Horm Metab Res. 2011 Mar;43:223-5.

14 Lehmann U, Riedel A, Hirche F, Brandsch C, Girndt M, Ulrich C, et al. Vitamin D3 supplementation: response and predictors of vitamin D3 metabolites: a randomized controlled trial. Clin Nutr. 2015 May 19;35:351-8.

15 Seibert E, Lehmann U, Riedel A, Ulrich C, Hirche F, Brandsch C, et al. Vitamin D3 supplementation does not modify cardiovascular risk profile of adults with inadequate vitamin D status. Eur J Nutr. 2017 Mar;56:621-34.

16 Seibert E, Heine GH, Ulrich C, Seiler S, Köhler $\mathrm{H}$, Girndt M. Influence of cholecalciferol supplementation in hemodialysis patients on monocyte subsets: a randomized, doubleblind, placebo-controlled clinical trial. Nephron Clin Pract. 2013;123:209-19. 